\title{
Physical Activity in Pregnancy was Favorably Associated with Maternal And Offspring Health Indices
}

\author{
K.D. Tambalis ${ }^{a, b,{ }^{*},}$ G. Arnaoutis ${ }^{a}$, L.S. Sidossis ${ }^{a, c}$
}

a Department of Nutrition and Dietetics, School of Health Science \& Education, Harokopio University, Athens, Greece.

${ }^{b}$ Department of Physical Education and Sport Science, National and Kapodistrian University of Athens, Greece

c Department of Kinesiology and Health, Rutgers University, New Brunswick, NJ 08901, USA

*Corresponding Author Tel: +302109549158, e-mail: dp425603@hua.gr

DOI: https://doi.org/10.34256/ijpefs2215

Received: 03-12-2021, Revised: 01-03-2022; Accepted: 02-03-2022; Published: 04-03-2022

Abstract: Regular physical activity (PA) in pregnancy can benefit the pregnant woman through a shorter birth and a shorter recovery period. The study aimed to investigate the effect of PA in pregnancy, on maternal and offspring health indicators. Population-based data were obtained from a national database that included anthropometric and physical fitness data of almost all Greek children 8 to 9 years. A random sample of 5,125 dyads of mothers-children was evaluated. Telephone interviews were carried out with the use of a standardized questionnaire for the collection of maternal lifestyle factors. Children born to mothers who participated in the recommended PA levels had lower odds (OR=0.78, 95\% CI: $0.69-0.95)$ to be overweight/obese in childhood. Adequate PA levels in pregnancy were found to be associated with lower odds of preterm birth by $61 \%$ (OR $=0.39,95 \% \mathrm{CI}: 0.17-0.87$ ), and alcohol consumption in pregnancy by $62 \%(\mathrm{OR}=0.38,95 \% \mathrm{CI}: 0.27-0.56)$ as compared to the inadequate level of PA. Also, mothers with adequate PA in pregnancy had decreased odds for excessive GWG and final BMI by almost $40 \%$ in comparison to those with inadequate PA levels. PA in pregnancy does seem to be related to offspring health indicators (e.g. obesity at 8 years) and is associated with a more favorable maternal health profile.

Keywords: Physical activity, Pregnancy, Health, Mother, Children

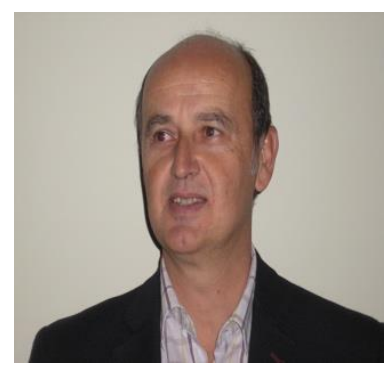

Konstantinos

Tambalis, (MSc, MSc, PhD) is a Teaching and Research Associate at the Department of Nutrition and Dietetics of the Harokopio University and National and Kapodistrian University of Athens in Greece. His research interests are in the areas of physical activity, Physical Education, athletic nutrition, diet and epidemiology of exercise.

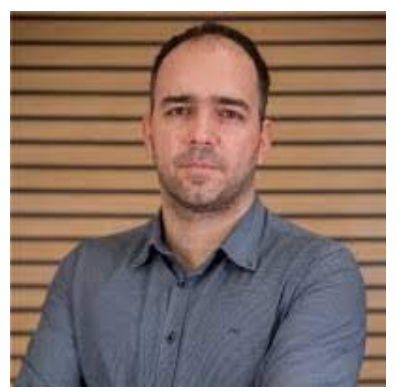

Giannis Arnaoutis, (MSc, PhD) is a Teaching and Research Assistant at the Department of Nutrition and Dietetics of the Harokopio University in Greece. His research interests are in the areas of athletic nutrition,

fitness training, strength \& conditioning, exercise physiology and exercise performance.

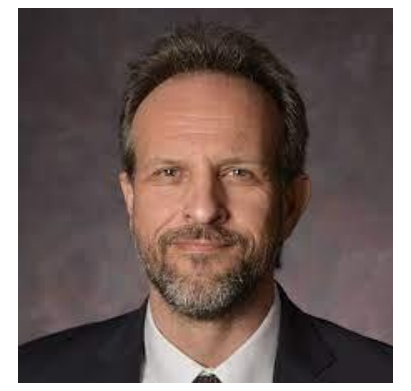

wellness and healthy metabolism, nutrition and exercise performance.

Labros S. Sidossis (MSc, $\mathrm{PhD})$ is a Distinguished Professor at the Department of Kinesiology and Health of the Rutgers University of New Jersey (USA). His research interests are in the areas of metabolism, lifestyle, adipose tissue, 


\section{Introduction}

Participation in regular physical activity (PA) and Physical activity (PA), quality of life, and health are strongly interrelated [1]. Chronic disease factors such as cardiovascular disease, hypertension, type 2 diabetes, and a sedentary lifestyle are present not only in adults but also in children [2]. Increasing the incidence of these diseases is significantly associated with lifestyle changes, specifically PA engagement, eating behaviors, and smoking [3]. According to the World Health Organization (WHO) all individuals aged 18-64 years should perform at least 150 min per week of moderate-intensity PA, or 75 min per week of highintensity PA, or a combination of these [4]. Pregnancy is a phase of a woman's life during which there is a greater awareness of her health. During pregnancy, the female body experiences a set of cardiovascular, hormonal, and metabolic changes such as changes in maternal physiology, production of hormones by the fetus and placenta, and increased fetal metabolism [5]. Many of the physiological and metabolic changes observed during pregnancy (e.g., increased resting heart rate, cardiac output, respiratory rate, temperature, glucose utilization, and energy needs) also occur during PA [5]. In previous years, pregnant women were advised not to participate in PA based mainly based on empirical evidence [6]. Initial findings in the topic speculated that the interaction of PA with pregnancy raised concerns about the possible redistribution of oxygenated blood and nutrients away from the placenta to the exercised muscles, assuming this process could restrict fetal development and birth weight [7]. The Center for Disease Control and Prevention (CDC) guidelines (2021) recommend that healthy women should participate in at least 150 minutes per week (for example, 30 minutes a day, five days a week) of moderate-intensity PA during pregnancy and the postpartum period [8]. Physical inactivity can contribute to excessive weight gain in pregnancy, increased risk of gestational diabetes, gestational hypertension, and more frequent side effects such as nausea, insomnia, leg cramps, burning sensation, swelling, joint pain, etc. [9]. Moreover, the fetus may experience changes in its development or maturation, changes in glycemic indexes and/or metabolic disorders, high or low birth weight, preterm birth, difficult birth, or even fetal stress $[6,10]$. Scientific findings proposed that regular PA before and during pregnancy improves maternal's cardiorespiratory status, reduces the risk of gestational diabetes, regulates blood pressure, and increases the incidence of full-term delivery [11-14]. Moreover, a meta-analysis showed that lifestyle, diet, and PA counseling prevent weight gain, while no significant changes were incorporated concerning cesarean section, large birth size for gestational age and macrosomia, and birth weight [14].

Scientific evidence supports the notion that PA during pregnancy is favorable not only for mother and fetus during gestation but also benefits persisting for the offspring into adulthood [14, 15]. Normalization of birth measures, such as birth weight, occurs when the mother engages in recommended PA throughout gestation [15]. Measures of development and growth show that PA during pregnancy could stimulate healthy growth throughout childhood [16]. Several PA interventions have been done to prevent overweight and obesity in children; however, it seems that the earliest intervention to treat these conditions is during pregnancy. Specifically, it is considered that PA in pregnancy may contribute positively to the prevention of childhood obesity $[15,16]$. The developmental origins hypothesis states that the in-utero environment influences, or programs, fetal organ development, which has implications for the infants after birth into adulthood [17]. A potential clarification for the progress of physical fitness (PF) is through developmental programming [17]. For example, scientific data suggest that maternal's pre-pregnancy body mass index and gestational weight gain were adversely associated with offspring's birth weight [18], offspring with low birth weight, a marker of adverse in utero environment, present reduced muscular strength, and aerobic fitness $[19,20]$. Research on animals showed that pre-pregnancy obesity is associated with reduced offspring aerobic fitness and muscular strength, suggesting that reduced PF could partially explain how an unfavorable intrauterine environment predisposes to the development of metabolic diseases [21].

There are scarce available data examining the possible association of PA during pregnancy with both, maternal's and offspring health issues, so the need arises to investigate them through broad representative epidemiological research.

Thus, considering the persistent controversies on this issue, the present study aims to explore the association between PA during pregnancy and the occurrence of maternal-child health outcomes taking into consideration several covariates. 


\section{Materials and Methods}

\subsection{Participants}

Population-based data derived from a national school-based health survey was obtained from a database that included PF and anthropometric data, as well as contact details and information (age, gender, city, and area of living, etc.) of almost all Greek children 8 to 9 years old who attended primary school during 2017. The national database was in almost all schools of Primary Education (roughly 85\%); schools that did not participate were from borderland areas, with small numbers of children. Thus, a total of 65,828 8- to 9 -year-old children ( $51 \%$ boys and $49 \%$ girls, over $95 \%$ of the total student population) participated in the study. Measurements were performed by two trained Physical Education (PE) teachers in each school. PE teachers followed a specific protocol taught in corresponding seminars held by the Greek General Secretariat of Sports (GSS). The same protocol was employed in all schools.

For this work, and feasibility reasons, a sample of 5,500 children $(0.8 \%$ of the entire population) was randomly extracted from the database and their mothers were contacted by telephone. Random extraction was performed through statistical software. The number of 5,500 subjects was adequate to achieve statistical power greater or equal to $99 \%$ for evaluating a $0.10 \pm 0.05$ change in the regression coefficients at a $5 \%$ significance level of two-sided tested hypotheses. The random sampling was stratified according to the region and place of living (e.g., rural/urban), according to the National Statistical Agency. The sample of 5,125 mother-father-child triads covered all geographical regions of Greece (e.g., mainland Greece and the islands). The information of the proposed protocol was collected through telephone interviews based on the Computer-Aided Telephone Interviews (CATI) method. To validate the process, 100 face-toface interviews were conducted to check for discrepancies with the information collected by telephone. No such discrepancies were noted in any of the variables measured.

\subsection{Measures}

All the necessary information was collected using a standardized questionnaire, named the Childhood Obesity Pregnancy Determinants (ChOPreD) questionnaire, designed and developed with the collaboration of the Harokopio University Department of Nutrition \& Dietetics and Department of Geography and the University of Texas Medical Branch Department of Internal Medicine-Geriatrics, Sealy Centre on Aging. The ChOPreD questionnaire was tested and internally revised by the study's investigators during a pilot study, which confirmed its construct validity. Thus, several potential confounders related to offspring's PF and obesity statuses, such as breastfeeding, paternal and maternal BMI, and maternal pregnancy conditions (i.e. smoking) were considered. Furthermore, mothers were asked whether their child was born on the projected birth date or not, whether the pregnancy was the result of an IVF (In Vitro Fertilization) or not, etc. As far as the offspring is concerned, all children born in Greece receive a health book from the state that records their birth weight and height and is subsequently filled with additional details by paediatricians during routine check-ups or visits due to illness. Only children that had a full set of records (e.g., health books) were included in the study, which finalized the sample of 5,125 mother-father-child triads. The BMI data for the offspring at the ages of 8 were calculated based on data retrieved from the national database. The BMI status of the offspring was determined based on cut-off points suggested by Cole and his colleagues [22]. During data collection, the mothers were asked to provide information on their PA engagement during pregnancy. For the current study, PA is defined as any form of bodily movement produced by skeletal muscles that increase energy expenditure over the level of physical rest, thereby offering numerous benefits for the human body. This can include a wide range of activities, such as leisure activities, participation in organized sports, exercise, physical work, etc. [23].

The assessment of PA was based on frequency (times/wk), and duration (e.g., exercise more than the recommended 30 minutes per day) of PA. The questionnaire did not evaluate the intensity, as only mild intensity exercise is recommended during pregnancy [24]. The questionnaire took into account activities undertaken during recreation, exercise, or sport, as well as daily activities (e.g., activities one does at work, as part of house and yard work, etc.). Mothers were instructed to refer to all domains of PA during their pregnancy. Mothers were classified as having inadequate PA status if they engaged in physical activities less than 150 min per week [24]. The Eurofit PF test battery was used to evaluate children's PF levels, initially proposed by the Council of Europe, and used systematically from many European countries [25]. 
Table 1 Descriptive characteristics of the sample

\begin{tabular}{|c|c|c|c|}
\hline & All $(n=5125)$ & Boys $(n=2686)$ & Girls $(n=2439)$ \\
\hline \multicolumn{4}{|l|}{ Offspring characteristics } \\
\hline Age (years) & $8.5(0.5)$ & $8.4(0.5)$ & $8.5(0.5)$ \\
\hline Birth weight (kg) & $3.4(0.5)$ & $3.4(0.5)$ & $3.3(0.5)$ \\
\hline BMI at birth $\left(\mathrm{kg} / \mathrm{m}^{2}\right)$ & $12.6(1.7)$ & $12.7(1.7)$ & $12.5(1.7)$ \\
\hline BMI at 1 -y-old $\left(\mathrm{kg} / \mathrm{m}^{2}\right)$ & $17.0(2.1)$ & $17.1(2.1)$ & $16.8(2.1)$ \\
\hline BMI at 2-y-old $\left(\mathrm{kg} / \mathrm{m}^{2}\right)$ & $16.5(2.4)$ & $16.6(2.4)$ & $16.4(2.3)$ \\
\hline BMI at 2-y-old $\left(\mathrm{kg} / \mathrm{m}^{2}\right)$ & $17.6(3.0)$ & $17.7(3.0)$ & $17.6(3.0)$ \\
\hline Breastfeeding, months & $3.2(3.8)$ & $3.1(3.8)$ & $3.2(3.8)$ \\
\hline \multicolumn{4}{|l|}{ Physical fitness } \\
\hline Vertical jump (cm) & $20.3(5.2)$ & $20.9(5.2)^{*}$ & $19.6(5.1)$ \\
\hline Small ball throw $(\mathrm{m})$ & $4.5(1.9)$ & $4.8(2.0)^{*}$ & $4.2(1.7)$ \\
\hline 30-meter sprint (s) & $6.5(0.7)$ & $6.4(0.7)^{*}$ & $6.6(0.7)$ \\
\hline 20-meter shuttle run (laps) & $3.2(1.9)$ & $3.3(2.0)^{*}$ & $3.0(1.8)$ \\
\hline \multicolumn{4}{|l|}{ Maternal characteristics } \\
\hline Age (years) & $34.9(4.8)$ & $34.9(4.8)$ & $34.8(4.8)$ \\
\hline Maternal age at childbirth (years) & $28.0(4.8)$ & $28.0(4.8)$ & $28.0(4.8)$ \\
\hline Pre-preqnancy BMI, $\mathrm{kg} / \mathrm{m}^{2}$ & $22.4(3.2)$ & $22.5(3.2)$ & $22.4(3.1)$ \\
\hline BMI after pregnancy, $\mathrm{kg} / \mathrm{m}^{2}$ & $26.0(4.5)$ & $26.1(4.5)$ & $25.8(4.5)$ \\
\hline Gestational weight gain, kg & $14.1(5.0)$ & $14.2(4.9)$ & $14.1(5.0)$ \\
\hline Gestational age (weeks) & $39.2(1.2)$ & $39.2(1.3)$ & $39.2(1.2)$ \\
\hline Preterm birth, $\mathrm{n}(\%)$ & $349(6.8 \%)$ & $186(6.9 \%)$ & $163(6.7 \%)$ \\
\hline Pregnancy in vitro, $\mathrm{n}(\%)$ & $51(1.3 \%)$ & $27(1.3 \%)$ & $24(1.3 \%)$ \\
\hline Parity before, $\mathrm{n}(\%)$ & $2528(49.5 \%)$ & $1294(48.3 \%)$ & $1234(50.8 \%)$ \\
\hline \multicolumn{4}{|l|}{ Maternal education, n (\%) } \\
\hline Basic $(\leq 6$ years) $(\%)$ & $696(13.5 \%)$ & $357(13.3 \%)$ & $339(13.9 \%)$ \\
\hline Secondary ( $\leq 12$ years) $(\%)$ & $2230(43.6 \%)$ & $1159(43.2 \%)$ & $1070(44.0 \%)$ \\
\hline Higher ( $>12$ years) $(\%)$ & $2191(42.8 \%)$ & $1168(43.5 \%)$ & $1023(42.1 \%)$ \\
\hline Physical activity in pregnancy, d/wk & $0.6(0.9)$ & $0.6(0.9)$ & $0.6(0.9)$ \\
\hline Inadequate PA ( $<150 \mathrm{~min} / \mathrm{wk})$ & $4161(81.2 \%)$ & $2178(81.0 \%)$ & $1971(81.1 \%)$ \\
\hline Adequate PA (>150 min/wk) & $964(18.8 \%)$ & $508(19.0 \%)$ & $457(18.9 \%)$ \\
\hline Smoking in pregnancy, $\mathrm{n}(\%)$ & $588(11.5)$ & $302(11.2)$ & $286(11.8)$ \\
\hline Alcohol consumption in pregnancy, $\mathrm{n}(\%)$ & $476(9.3 \%)$ & $250(9.3 \%)$ & $226(9.3 \%)$ \\
\hline Gestational diabetes, $\mathrm{n}(\%)$ & $97(1.9 \%)$ & $55(2.0 \%)$ & $42(1.7 \%)$ \\
\hline Gestational hypertension, $\mathrm{n}(\%)$ & $117(2.3 \%)$ & $63(2.3 \%)$ & $54(2.2 \%)$ \\
\hline
\end{tabular}

The values are means \pm standard deviation unless otherwise indicated; PA, physical activity; BMI, body mass index; ${ }^{*} \mathrm{P}$-values $<0.05$ for differences between boys and girls.

Specifically, for the current study, four fitness tests were administered by two trained $\mathrm{PE}$ professionals in each school: a) Vertical jump (VJ; jump from a squatting position at the start) assess lower-body explosive power; b) Small ball throw (SBT; $1 \mathrm{~kg}$ with both hands in a standing position), to assess upper body explosive strength; c) 30-meter sprint (30mS; from a standing start), to evaluate speed; and d) Multi-stage 20-meter shuttle run, (20mSRT), to estimate CRF. The 20mSRT test consists of measuring the number of laps completed by subjects running up and down between two lines, set 20 meters apart, at an initial speed of $8.5 \mathrm{~km} / \mathrm{h}$ which increases by 0.5 $\mathrm{km} / \mathrm{h}$ every minute, using a pre-recorded audiotape. The above widely-used five PF tests were selected as being representative of explosive, anaerobic, and aerobic performance. Repeat tests (2 trials) were allowed for the VJ, SBT, and $30 \mathrm{mS}$, with the best performance of each recorded.
Students' performance in PF tests was evaluated based on the PF normative age- and sex-specific values for 8to-10-year-old Greek boys and girls. Particularly, for each of the five PF tests applied, a performance $\leq 25$ th percentile was considered as low, between the 25th and 75 th as average and $\geq 75$ th as high [26].

\subsection{Statistical analysis}

Categorical variables were presented as absolute and relative frequencies. Continuous variables were presented as mean values \pm standard deviations (SD). Histograms and P-P plots were applied to evaluate the normality of the distribution of the continuous variables. Comparisons between differences of mean values of normally distributed variables between groups of PA status were tested using the Student t-test and the chi-square test evaluated associations between the categorical variables. To assess the potential associations between PA in 
pregnancy (as a continuous variable) with maternal's and offspring health indices, we applied linear regression analysis in an extended model approach (assumptions of linearity and normal distributions were checked and met), and beta weights (b) were calculated. Model 1 included only the predictor (PA in pregnancy) and the dependent variable (e.g., CRF). For Model 2, a set of confounders relating to children (i.e., sex, children's BMI at 8-9 y, and breastfeeding months) was added into the model. For Model 2, also potential confounders relating to the mother, such as final maternal BMI, gestational age, maternal age at birth, pregnancy in vitro, preterm delivery, parity before, educational level, smoking during pregnancy, were added into the model. Before that, every possible effect modification between the risk factors and the confounders was examined, but all interaction terms were not statistically significant ( $P$-values $>0.05$ ). Moreover, to assess the potential effect of PA status in pregnancy (adequate vs. inadequate) on maternal's and offspring health indices (e.g. obesity status, PF, preterm born, diabetes and e.tc.), stepwise binary logistic regression analysis was applied and odds ratios (ORs) with the corresponding $95 \%$ confidence intervals (CIs) were calculated. The Hosmer and Lemeshow's goodness-of-fit test was calculated to evaluate the model's goodness-of-fit and residual analysis was implicated using the dbeta, the leverage, and Cook's distance $D$ statistics to identify outliers and influential observations. All analyses were performed using the SPSS version 18.0 software for Windows (SPSS Inc., Chicago, IL, USA). Statistical significance level from two-sided hypotheses was accepted at the $5 \%$ level $(p \leq 0.05)$.

\section{Results and Discussion}

The descriptive characteristics of mothers and their offspring (by sex) are presented in Table 1 . The analysis revealed that the mean frequency of PA ( $\geq 30$ $\mathrm{min} /$ day) in pregnancy was $0.6 \pm 0.9$ days/wk. A great percentage $(64.5 \%)$ of mothers was classified as physically inactive (<30 min/day) during pregnancy, while $16.7 \%$ of them was classified as physically active moderately (1-3 days/wk), $13.8 \%$ sometimes (45 days/wk), $3.2 \%$ very often ( 6 days/wk) and $1.8 \%$ daily.

We did not find significant differences in children's BMI between mothers with adequate PA in pregnancy ( $>150 \mathrm{~min} / \mathrm{wk}$ ) as compared to those with inadequate PA $(<150 \mathrm{~min} / \mathrm{wk})$. Also, wedid not observe significant differences in PF test performances, between mothers with adequate PA as compared to those with inadequate PA in pregnancy (Table 2). On the contrary, we revealed significant differences in maternal's before and current BMI between mothers with adequate PA and those with inadequate PA during pregnancy, while, we additionally incorporated significant differences among PA categories in the incidence of preterm birth (Table 2).

Table 3 presents linear regression models showing the estimated change in the mean of several maternal's and offspring characteristics per PA days/week in pregnancy. In the unadjusted analysis (Model 1), PA in pregnancy was positively associated with birth weight and breastfeeding months and negatively associated with BMI at 8 years (all pvalues $<0.05$ ). Furthermore, $P A$ in pregnancy was positively associated with maternal's characteristics such as gestational age and negatively associated with BMI before pregnancy, final BMI, and current BMI and GWG (all $p$-values $<0.05$ ). These associations continued to be statistically significant after controlling for several children's and mothers' characteristics. For example, each day per week increase in PA during pregnancy was associated with a $0.02 \mathrm{~kg}$ increase in weight birth (95\% CI, 0.0094 to $0.05, p=0.003$ ).

Given that significant differences in several offspring's and maternal's health indices were considered between PA levels (inadequate vs. adequate) in pregnancy, we applied binary logistic regression analysis to explore it separately (Tables $4 \&$ 5). Children aged 8 years old whose mothers had adequate PA levels in pregnancy had lower odds of overweight/obesity by $22 \%$ as compared to their peers from mothers with inadequate PA levels after adjustment for birth weight, BMI, breastfeeding, and physical fitness tests performances (Table 4). In parallel, mothers with adequate PA in pregnancy had decreased odds for excessive GWG and final BMI by almost $40 \%$ in comparison to those with inadequate PA levels (Table 5). Moreover, maternal PA levels in pregnancy were found to be favorably associated with preterm birth (OR=0.44, 95\%CI: 0.20-0.82) and avoidance of alcohol consumption in pregnancy (OR=1.46, 95\%CI: 1.33-1.64), after adjustment for several covariates (Table 5 ). 
Table 2 Participants' characteristics by physical activity level in pregnancy.

\begin{tabular}{|c|c|c|}
\hline & $\begin{array}{c}\text { Adequate physical } \\
\text { activity }(>150 \mathrm{~min} / \mathrm{wk}\end{array}$ & $\begin{array}{l}\text { Inadequate physical } \\
\text { activity }(<150 \mathrm{~min} / \mathrm{wk})\end{array}$ \\
\hline \multicolumn{3}{|l|}{ Offspring characteristics } \\
\hline Sex (male), $\mathrm{n}(\%)$ & $129(50.2)$ & $2557(52.6)$ \\
\hline Sex (female), n (\%) & $128(49.8)$ & $2300(47.4)$ \\
\hline Weight at birth (kg) & $3.4(0.5)$ & $3.3(0.5)$ \\
\hline BMI at birth $\left(\mathrm{kg} / \mathrm{m}^{2}\right)$ & $12.7(1.6)$ & $12.6(1.7)$ \\
\hline BMI at 1-y-old $\left(\mathrm{kg} / \mathrm{m}^{2}\right)$ & $17.0(1.9)$ & $16.9(2.1)$ \\
\hline BMI at 2-y-old $\left(\mathrm{kg} / \mathrm{m}^{2}\right)$ & $16.4(2.3)$ & $16.5(2.4)$ \\
\hline BMI at 8 -y-old $\left(\mathrm{kg} / \mathrm{m}^{2}\right)$ & $17.4(3.0)$ & $17.7(3.0)^{*}$ \\
\hline Breastfeeding (months) & $3.1(4.0)$ & $3.1(3.8)$ \\
\hline \multicolumn{3}{|l|}{ Physical fitness components } \\
\hline Vertical jump (cm) & $20.3(5.3)$ & $20.3(5.2)$ \\
\hline Standing long jump (cm) & $88(16.6)$ & $88(16.2)$ \\
\hline Small ball throw $(\mathrm{m})$ & $4.3(1.3)$ & $4.4(1.9)$ \\
\hline 30-meter sprint (s) & $6.2(0.6)$ & $6.4(0.7)$ \\
\hline 20-meter shuttle run (laps) & $3.2(1.8)$ & $3.2(1.9)$ \\
\hline \multicolumn{3}{|l|}{ Maternal characteristics } \\
\hline BMI before pregnancy, $(\mathrm{kg} / \mathrm{m} 2)$ & $21.7(2.8)$ & $22.5(3.2) *$ \\
\hline BMI final, $\left(\mathrm{kg} / \mathrm{m}^{2}\right)$ & $22.5(3.0)$ & $22.5(3.0)$ \\
\hline BMI current, $\left(\mathrm{kg} / \mathrm{m}^{2}\right)$ & $24.9(4.3)$ & $26.1(4.5)^{*}$ \\
\hline Maternal age at childbirth (y) & $28.24(4.8)$ & $27.8(4.7)$ \\
\hline Gestational age (weeks) & $39.4(1.2)$ & $39.1(1.6)$ \\
\hline Preterm birth, (\%) & 3.1 & $7.0^{*}$ \\
\hline Pregnancy in vitro, (\%) & 2.1 & 1.4 \\
\hline Parity before, $(\%)$ & 48.5 & 49.6 \\
\hline Gestational diabetes, (\%) & 1.6 & 1.9 \\
\hline Gestational hypertension, (\%) & 1.6 & 2.3 \\
\hline Smoking during pregnancy, (\%) & 12.5 & 11.6 \\
\hline Alcohol consumption, (\%) & 7.4 & $9.8^{*}$ \\
\hline Secondary/High educational level, & 83.1 & 86.0 \\
\hline \multicolumn{3}{|c|}{$\begin{array}{l}\text { Values are presented as Mean } \pm \text { standard deviation (SD) or percentages (\%). BMI, } \\
\text { body mass index; } * P<0.05 \text { for differences between adequate and inadequate } \\
\text { physical activity status. }\end{array}$} \\
\hline
\end{tabular}

Table 3 Linear regression statistics (b, 95\%CI) showing associations of physical activity in pregnancy with maternal's and offspring health indices.

Maternal's physical activity days per week

(with at least 30 min of moderate PA in pregnancy)

\begin{tabular}{|c|c|c|c|c|}
\hline & \multicolumn{2}{|l|}{ Model 1 (unadjusted) } & \multicolumn{2}{|l|}{ Model 2 (adjusted) } \\
\hline & b $(95 \% \mathrm{CI})$ & P-value & b $(95 \% \mathrm{CI})$ & P-value \\
\hline \multicolumn{5}{|l|}{ Offspring characteristics } \\
\hline Weight at birth (kg) & $0.02(0.007,0.04)$ & 0.005 & $0.02(0.009,0.05)$ & 0.003 \\
\hline BMI at birth $\left(\mathrm{kg} / \mathrm{m}^{2}\right)$ & $0.03(-0.02,0.08)$ & 0.290 & $0.03(-0.04,0.09)$ & 0.312 \\
\hline BMI at 1 -y-old $\left(\mathrm{kg} / \mathrm{m}^{2}\right)$ & $0.02(-0.07,0.11)$ & 0.683 & $0.02(-0.10,0.15)$ & 0.796 \\
\hline BMI at 2-y-old $\left(\mathrm{kg} / \mathrm{m}^{2}\right)$ & $-0.10(-0.22,0.03)$ & 0.118 & $-0.09(-0.20,0.02)$ & 0.326 \\
\hline BMI at 8-y-old $\left(\mathrm{kg} / \mathrm{m}^{2}\right)$ & $-0.13(-0.21,-0.04)$ & 0.004 & $-0.11(-0.19,-0.02)$ & 0.007 \\
\hline $\begin{array}{l}\text { Breastfeedina (months) } \\
20 \text {-meter shuttle run (stages) }\end{array}$ & $\begin{array}{l}0.22(0.11,0.33) \\
0.02(-0.03,0.08)\end{array}$ & $<0.001$ & $0.19(0.08,0.29)$ & 0.004 \\
\hline $\begin{array}{l}\text { 20-meter shuttle run (stages) } \\
\text { Standinglongjump }(\mathrm{cm})\end{array}$ & $\begin{array}{l}0.02(-0.03,0.08) \\
0.25(-0.62,1.12)\end{array}$ & $\begin{array}{l}0.446 \\
0.567\end{array}$ & $\begin{array}{l}0.02(-0.04,0.10) \\
0.20(-0.56,1.02)\end{array}$ & $\begin{array}{l}0.538 \\
0.663\end{array}$ \\
\hline Verticaljump (cm) & $0.02(-0.13,0.17)$ & 0.796 & $0.02(-0.11,0.15)$ & 0.699 \\
\hline Smallballthrow (m) & $0.03(-0.05,0.11)$ & 0.218 & $0.02(-0.04,0.12)$ & 0.456 \\
\hline 30-meter sprint(s) & $-0.03(-0.05,-0.01)$ & 0.074 & $-0.03(-0.06,-0.01)$ & 0.075 \\
\hline
\end{tabular}

\section{Maternal's characteristics}


BMI final, $\left(\mathrm{kg} / \mathrm{m}^{2}\right)$

BMI current, $\left(\mathrm{kg} / \mathrm{m}^{2}\right)$

Gestational Weight Gain (kg)

Maternal age at childbirth ( $y$ )

Gestational aqe (weeks)

Number of children before, ( $n$ )

Cigarettes during pregnancy,

Glasses of alcohol
$<0.00$

0.002

$<0.00$

0.194

0.004

0.542

0.351

0.016

$\begin{array}{cc}-0.22(-0.33,-0.11) & 0.007 \\ -0.19(-0.31,-0.07) & 0.005 \\ -0.38(-0.50,-0.22) & <0.001 \\ 0.07(-0.07,0.25) & 0.296 \\ 0.06(0.01,0.13) & 0.005 \\ 0.01(-0.03,0.04) & 0.623 \\ 0.03(-0.06,0.14) & 0.467 \\ -0.21(-0.42,-0.13) & 0.041\end{array}$

0.041

BMI, body mass index; CI, confidence interval. Note: Model 1: Unadjusted; Model 2: Adjusted for children's and mother's characteristics.

Table 4 Results (OR, 95\%CI) from logistic regression models used to evaluate the association of maternal's physical activity status in pregnancy (inadequate vs. adequate) on offspring's health indices.

\begin{tabular}{|c|c|c|c|}
\hline \multirow[b]{3}{*}{ Predictors } & \multicolumn{3}{|c|}{$\begin{array}{l}\text { Maternal's physical activity status in pregnancy } \\
\text { (inadequate vs. adequate) }\end{array}$} \\
\hline & Model 1 & Model 2 & Model 3 \\
\hline & OR $(95 \% \mathrm{CI})$ & OR $(95 \% \mathrm{CI})$ & OR $(95 \% \mathrm{CI})$ \\
\hline \multicolumn{4}{|l|}{ Offspring characteristics } \\
\hline Birth weight (normal vs. low) & $0.85(0.44-1.62)$ & $0.83(0.49-1.68)$ & $0.88(0.54-1.43)$ \\
\hline $\begin{array}{l}\text { BMI at 1-y-old (normalweight vs. } \\
\text { overweight/obese) }\end{array}$ & $0.65(0.23-1.44)$ & $0.67(0.25-1.49)$ & $0.69(0.21-1.22)$ \\
\hline $\begin{array}{l}\text { BMI at 2-y-old (normalweight vs. } \\
\text { overweight/obese) }\end{array}$ & $0.56(0.20-1.57)$ & $0.57(0.19-1.49)$ & $0.64(0.31-1.12)$ \\
\hline $\begin{array}{l}\text { BMI at } 8 \text {-y-old (normalweight vs. } \\
\text { overweight/obese) }\end{array}$ & $0.77(0.65,0.89)$ & $0.77(0.66,0.89)$ & $0.78(0.69,0.95)$ \\
\hline Breastfeeding $\geq 6$ months (Yes vs. No) & & $0.87(0.59-1.29)$ & $0.87(0.59-1.29)$ \\
\hline $\begin{array}{l}\text { Multi-stage } 20 \text {-meter shuttle run (average/high } \\
\text { vs. low) }\end{array}$ & & & $1.00(0.73,1.39)$ \\
\hline Vertical jump (average/high vs. low) & & & $0.97(0.72,1.31)$ \\
\hline Standing long jump (average/high vs. low) & & & $0.94(0.54,1.64)$ \\
\hline Small ball throw (average/high vs. low) & & & $0.83(0.62,1.12)$ \\
\hline 30-meter sprint (average/high vs. low) & & & $0.78(0.48,1.21)$ \\
\hline Total physical fitness (average/high vs. low) & & & $0.93(0.70,1.23)$ \\
\hline
\end{tabular}

Abbreviations: BMI, body mass index; CI, confidence interval; OR, odds ratio. Note: Model 1, adjusted for children's sex + BMI; Model 2, model $1+$ breastfeeding; Model 3, model $2+$ physical fitness tests performances.

\subsection{Discussion}

Pregnancy is a unique time when women are motivated to modify some unfavorable habits and to adopt a more physically active lifestyle. The current study aimed to explore the association of PA during pregnancy on an extensive range of maternal's and child health indices. Findings from this broad, representative cohort proposed that: (a) offspring whose mothers had adequate PA levels had lower odds of overweight/obesity in childhood as compared to their peers with inadequate maternal PA levels; (b) Mothers with adequate PA levels had lower odds for overweight/obesity throughout gestation period and after it, and; (c) PA in pregnancy was favorably associated with preterm birth and alcohol consumption; All the above-mentioned associations remained statistically significant after adjustment for several covariates.

The current data showed that a low percentage of mothers $(18.9 \%)$ reported adequate PA levels (>150 $\mathrm{min} / \mathrm{wk}$ of moderate-intensity) during pregnancy. Similarly, with our results, review studies revealed that percentages of $15 \%$ to $20 \%$ of women adhere to the recommendations relating to PA in pregnancy, globally, while, it seems that pregnant women were less physically active than non-pregnant women and that pregnancy leads to a diminish in PA $[27,28]$. 
Table 5 Results (OR, 95\%CI) from logistic regression models used to evaluate the association of maternal's physical activity status in pregnancy (inadequate vs. adequate) on maternal health indices.

\begin{tabular}{|c|c|c|c|}
\hline & \multicolumn{3}{|c|}{$\begin{array}{l}\text { Maternal's physical activity status in pregnancy } \\
\text { (inadequate vs. adequate) }\end{array}$} \\
\hline & Model 1 & Model 2 & Model 3 \\
\hline Maternal characteristics & OR $(95 \% \mathrm{CI})$ & OR $(95 \% \mathrm{CI})$ & OR $(95 \% \mathrm{CI})$ \\
\hline $\begin{array}{l}\text { BMI status before pregnancy, (normalweight } \\
\text { vs. overweight/obese) }\end{array}$ & $0.73(0.56,0.94)$ & $0.74(0.57,0.95)$ & $0.75(0.60,0.91)$ \\
\hline $\begin{array}{l}\text { BMI status final, (normalweight vs. } \\
\text { overweight/obese) }\end{array}$ & $0.56(0.43-0.73)$ & $0.58(0.45-0.77)$ & $0.58(0.44-0.79)$ \\
\hline $\begin{array}{l}\text { BMI status current, (normalweight vs. } \\
\text { overweight/obese) }\end{array}$ & $0.74(0.57-0.95)$ & $0.74(0.58-0.95)$ & $0.76(0.61-0.92)$ \\
\hline $\begin{array}{l}\text { Gestational Weight Gain (accepted vs. } \\
\text { excessive) }\end{array}$ & $0.58(0.44-0.77)$ & $0.59(0.42-0.78)$ & $0.60(0.45-0.76)$ \\
\hline Maternal age at childbirth (<35y vs. $>35 y$ ) & & $1.29(0.80-2.06)$ & $1.27(0.78-2.12)$ \\
\hline Preterm birth, (<37 vs. $37 \geq$ weeks) & & $0.42(0.21,087)$ & $0.44(0.20,082)$ \\
\hline $\begin{array}{l}\text { Type of conception (normal vs. in vitro } \\
\text { fertilization) }\end{array}$ & & $0.60(0.21,1.68)$ & $0.63(0.29,1.72)$ \\
\hline Parity before, (yes vs. no) & & $0.97(0.75,1.24)$ & $0.93(0.70,1.12)$ \\
\hline Primary vs. Secondary/High educational level & & $1.48(0.97-2.25)$ & $1.44(0.89-2.03)$ \\
\hline Gestational diabetes, (yes vs. no) & & & $1.23(0.45-3.39)$ \\
\hline Gestational hypertension, (yes vs. no) & & & $1.50(0.55-4.10)$ \\
\hline Smoking during pregnancy, (yes vs. no) & & & $0.91(0.62-1.33)$ \\
\hline Alcohol consumption, (yes vs. no) & & & $1.46(1.33-1.64)$ \\
\hline
\end{tabular}

Abbreviations: BMI, body mass index; CI, confidence interval; OR, odds ratio; Note: Model 1, adjusted for maternal's BMI + gestational weight gain; model 2, model $1+$ preterm birth + maternal age at birth + pregnancy in vitro + educational status; model 3, model $2+$ gestational diabetes + gestational hypertension + maternal smoking + alcohol consumption.

The maternal's PA level in pregnancy was found to be associated with the obesity status of the offspring in childhood. In line with our results, a study examining PA during pregnancy found that weightbearing PA at moderate intensity was associated with lower body weight in children aged 5-years, as compared to inactivity [29]. Furthermore, a study that conducted exercise interventions in pregnant mothers reported that the offspring of mothers who were engaged in a PA program during pregnancy had greater total body fat and abdominal adiposity in comparison to the control group [30]. Review studies speculated that PA in pregnancy could favorably contribute to the prevention of childhood obesity [15, 16]. According to a recent meta-analysis, prenatal PA could create a beneficial fetal milieu and reduce the offspring's risk of obesity in childhood through the regulation of body weight and cardiometabolic factors [31].
On contrary, a study that examined maternal's recreational PA during pregnancy proposed that it was not associated with offspring's risk of overweight in childhood, after adjustment for several covariates [32].

Also, another study showed that the offspring (aged 1 year) of women who engaged in PA regularly presented similar body weight with those of control subjects [33]. Potentially these discrepancies could be partially attributed to the type of the research (casecontrol, epidemiological), the offspring's age, the examined sample, e.tc, factors that might modify the association between maternal PA during pregnancy and the offspring's BMI status. Nevertheless, in our research, we have incorporated several probable confounders such as maternal's BMI, GWG, smoking during pregnancy, birth weight, etc, which had no significant effect on the estimates. The current data indicated that the maternal's adequate PA levels in 
pregnancy were favorably associated with her BMI status at the end of the gestation and several years later as well as with reduced odds for excessive GWG, compared to inadequate PA levels. In line with our results, a study showed that pregnant women who regularly engaged in a supervised PA program for 3 months gained excessive weight significantly less frequently and decreased body weight much faster after delivery as compared to the control group [34]. Physical inactivity may contribute, among other unfavorable health implications, to excessive GWG in pregnancy [9]. A higher level of PA in pregnancy was associated with lower GWG and a decreased risk of exceeding the Institute of Medicine's recommendations regarding GWG [35]. Furthermore, a meta-analysis speculated that alterations in lifestyle habits such as diet and PA could prevent excessive GWG [14], while a recent meta-analysis showed that the limitation of weight gain is among the maternal's health benefits due to PA in pregnancy [36]. Another review study including 65 randomized controlled trials found that the interventions group decreased the risk of excessive GWG by $20 \%$ on average than those in control groups [37]. In general, it seems that combined interventions focused on the adoption of recommended PA levels and proper dietary habits could result in a decisive influence on GWG.

The current findings indicated that recommended PA levels in pregnancy were associated with decreased odds of preterm birth. According to scientific evidence, physical inactivity during pregnancy could result in preterm birth $[6,10]$, while engagement in regular PA in pregnancy increases the incidence of full-term delivery [11-14]. Meta-analysis of 41 studies suggested that higher leisure-time PA is associated with a reduced risk of preterm birth [38].

Finally, our results proposed that adequate PA levels in pregnancy are associated with decreased odds of alcohol consumption in pregnancy. According to Centers for Disease Control and Prevention, alcohol consumption during pregnancy can cause miscarriage, stillbirth, and a wide range of a child's lifelong physical, behavioral, and intellectual disabilities such as small head size, shorter-than-average height, and low body weight etc. [39]. There are no comparative data available for the potential associations between alcohol consumption in pregnancy and lifestyle habits such as PA during pregnancy. Given the importance of PA in pregnancy as an indicator of maintaining and promoting maternal and offspring health, potentially, mothers who engaged in recommended PA levels adopt a healthier lifestyle by avoiding unhealthy habits such as drinking alcohol and smoking.

The main strength of this study was that conducted in a very large, representative sample of mother-child dyads, taking into consideration several covariates. Among potential limitations included that the perinatal information was collected during the telephone interviews to some extent was self-reported. Consequently, although mothers could provide information derived from health records for themselves, this consists of a limitation of the study. Particularly, this could be attributed to deliberate overreporting, under-reporting, or recall bias for the selfreported pre-pregnancy data. Also, the impact of possible confounders such as maternal nutrition, sexual maturity, and fat-free mass, and PA status of children, etc., were not included in the analysis.

\section{Conclusion}

To sum up, our analysis proposed that maternal's PA level was associated with offspring's overweight/obesity in childhood, while we did not observe a significant association between maternal's PA in pregnancy and child's PF components. Also, mothers with adequate PA levels in pregnancy had lower odds for overweight/obesity in gestation period and postpartum and for preterm birth and alcohol consumption, even after adjustment for several covariates.

\section{References}

[1] F.W. Booth, C.K. Roberts, \& M.J. Laye, Lack of Exercise Is a Major Cause of Chronic Diseases, Comprehensive Physiology, 2(2) (2012) 11431211. [DOI] [PubMed]

[2] 2.M.S. Tremblay, A.G. LeBlanc, M.E. Kho, T.J. Saunders, R. Larouche, R.C. Colley, G. Goldfield, \& S. C. Gorber, Systematic Review of Sedentary Behaviour and Health Indicators in School-Aged Children and Youth, International Journal of Behavioral Nutrition and Physical Activity, 8 (2011) 98. [DOI] [PubMed]

[3] T. Seppala, N. Hankonen, E. Korkiakangas, J. Ruusuvuori, \& J. Laitinen, National Policies for the Promotion of Physical Activity and Healthy Nutrition in the Workplace Context: A Behaviour Change Wheel Guided Content Analysis of Policy Papers in Finland, BMC Public Health, 18(10) (2017) 87. [DOI] [PubMed] 
[4] WHO: Global Recommendations on Physical Activity for Health, (2020) Assessed Nov 17, 2021.

[5] A.M. Panaitescu, M. R. Popescu, A.M. Ciobanu, N. Gica, \& B.A. Cimpoca-Raptis, Pregnancy Complications Can Foreshadow Future DiseaseLong-Term Outcomes of a Complicated Pregnancy, Medicina, 57(12) (2021) 1320. [DOI] [PubMed]

[6] S.K. Hinman, K.B. Smith, D.M. Quillen, \& M.S. Smith, Exercise in Pregnancy: A Clinical Review, Sports Health, 7(6), (2015) 527-531. [DOI] [PubMed]

[7] E.E. Nuss, \& A.C. Sciscione, Activity Restriction and Preterm Birth Prevention, Current Opinion in Obstetrics \& Gynecology, 34(2) (2022) 7781. [DOI] [PubMed]

[8] Physical Activity Recommendations for Pregnant and Postpartum Women, Centers for Disease Control and Prevention, (2021). https://www.cdc.gov/physicalactivity/basics/pr egnant-and-postpartum-women.html

[9] A. Garshasbi, \& S. Faghih Zadeh, The Effect of Exercise on the Intensity of Low Back Pain in Pregnant Women, International Journal of Gynaecology and Obstetrics, 88(3) (2005) 271275. [DOI] [PubMed]

[10] M.S. Poudevigne \& P.J. O'Connor, A Review of Physical Activity Patterns in Pregnant Women and Their Relationship to Psychological Health, Sports Medicine, 36(1) (2006) 19-38. [DOI] [PubMed]

[11] K. Melzer, Y. Schutz, M. Boulvain, \& B. Kayser, Physical Activity and Pregnancy: Cardiovascular Adaptations, Recommendations and Pregnancy Outcomes, Sports Medicine, 40(6) (2010) 493507. [DOI] [PubMed]

[12] D.K. Tobias, F.B. Hu, J.P. Forman, J. Chavarro, \& C. Zhang, Increased risk of Hypertension After Gestational Diabetes Mellitus: Findings from a Large Prospective Cohort Study, Diabetes Care, 34(7) (2011) 1582-1584. [DOI] [PubMed]

[13] S.S. Stutzman, C.A. Brown, S.M. Hains, M. Godwin, G. N. Smith, J. L. Parlow, \& B. S. Kisilevsky, The Effects of Exercise Conditioning in Normal and Overweight Pregnant Women on Blood Pressure and Heart Rate Variability, Biological Research for Nursing, 12(2) (2010) 137-148. [DOI] [PubMed]

[14] E. Oteng-Ntim, R. Varma, H. Croker, L. Poston, \& P. Doyle, Lifestyle Interventions for
Overweight and Obese Pregnant Women to Improve Pregnancy Outcome: Systematic Review and Meta-Analysis, BMC Medicine, 10 (2012) 47. [DOI] [PubMed]

[15] A. Gaston, \& A. Cramp, Exercise During Pregnancy: A Review of Patterns and Determinants, Journal of Science and Medicine Sport, 14(4) (2011) 299-305. [DOI] [PubMed]

[16] C. Moyer, O.R. Reoyo, \& L. May, The Influence of Prenatal Exercise on Offspring Health: A Review, Clinical Medicine Insights of Womens Health, 9 (2016) 37-42. [DOI] [PubMed]

[17] X. Zhao, Genetic Hypothesis for the Developmental Origins of Health and Disease Theory, Journal of Bio-X Research, 3(1) (2020) 36-43. [DOI]

[18] S. Mintjens, R. J. Gemke, M.N.M. van Poppel, T.G.M. Vrijkotte, T.J. Roseboom, \& A.W. van Deutekom, Maternal Pre-Pregnancy Overweight and Obesity are Associated with Reduced Physical Fitness but do not Affect Physical Activity in Childhood: The Amsterdam Born Children and their Development Study, Child Obesity, 15(1) (2019) 31-39. [DOI] [PubMed]

[19] R. Dodds, H.J. Denison, G. Ntani, R. Cooper, C. Cooper, A. A. Sayer, \& J. Baird, Birth Weight and Muscle Strength: A Systematic Review and Meta-Analysis. Journal of Nutrition, Health and Aging, 16(7) (2012) 609-615. [DOI] [PubMed]

[20] D.A. Lawlor, A.R. Cooper, C. Bain, G. D. Smith, A. Irwin, C. Riddoch, \& A. Ness, Associations of Birth Size and Duration of Breast Feeding with Cardiorespiratory Fitness in Childhood: Findings from the Avon Longitudinal Study of Parents and Children (ALSPAC), European Journal of Epidemiology, 23(6) (2008) 411422. [DOI] [PubMed]

[21] M. Raipuria, H. Bahari, \& M.J. Morris, Effects of Maternal Diet and Exercise During Pregnancy on Glucose Metabolism in Skeletal Muscle and Fat of Weanling Rats, PLoS One, 10(4) (2015) e0120980. [DOI] [PubMed]

[22] T.J. Cole, K.M. Flegal, D. Nicholls, \& A.A. Jackson, Body Mass Index Cut Offs to Define Thinness in Children and Adolescents: International Survey, British Medicine Journal, 335(7612) (2007) 194. [DOI] [PubMed]

[23] J.S. Kendrick, D.F. Williamson, \& C.J. Caspersen, A Meta-Analysis of Physical Activity in the Prevention of Coronary Heart Disease, 
American Journal of Epidemiology,132(4) (1990) 612-628. [DOI] [PubMed]

[24] K.R. Evenson, L. Chasan-Taber, D. S. Downs, \& E.E. Pearce, Review of Self-Reported Physical Activity Assessments for Pregnancy: Summary of the Evidence for Validity and Reliability, Paediatric and Perinatal Epidemiology, 26(5) (2012) 479-494. [DOI] [PubMed]

[25] Council of Europe. Committee of Experts on Sports Research, (1999) 2nd ed, Eurofit: Handbook for the Eurofit Tests of Physical Fitness, Strasbourg: Sports Division Strasbourg, Council of Europe Publishing and Documentation Service.

[26] K.D. Tambalis, D.B. Panagiotakos, G. Arnaoutis, \& L.S.Sidossis, Endurance, Explosive Power, and Muscle Strength in Relation to Body Mass Index and Physical Fitness in Greek Children Aged 7-10 Years, Pediatric Exercise Science, 25(3) (2013) 394-406. [DOI] [PubMed]

[27] A. Gaston, \& A. Cramp, Exercise During Pregnancy: A Review of Patterns and Determinants, Journal of Science and Medicine in Sports, 14(4) (2011) 299-305. [DOI] [PubMed]

[28] K.M. Borodulin, K.R. Evenson, F. Wen, A.H. Herring, \& A.M. Benson, Physical Activity Patterns During Pregnancy, Medicine \& Science in Sports\& Exercise, 40(11) (2008) 1901-1908. [DOI] [PubMed]

[29] J.F. Clapp $3^{\text {rd }}$ Morphometric and Neurodevelopmental Outcome at Age Five Years of the Offspring of Women Who Continued to Exercise Regularly Throughout Pregnancy, Journal of Pediatrics, 129(6) (1996) 856-863. [DOI] [PubMed]

[30] V. Chiavaroli, S.A. Hopkins, J. G. B. Derraik,]. B. Biggs, R. O. Rodrigues, C. H. Brennan, S. N.Seneviratne, C. Higgins, J. C.Baldi, L. M. E.McCowan, W. S. Cutfield, \&P. L. Hofman, Exercise in Pregnancy: 1-Year and 7-Year Follow-Ups of Mothers and Offspring After a Randomized Controlled Trial, Scientific Reports, 8(1) (2018) 12915. [DOI] [PubMed]

[31] L. Guillemette, J.L. Hay, D.S. Kehler, N. C. Hamm, C. Oldfield, J. M.McGavock, \& T. A. Duhamel, Exercise in Pregnancy and Children's Cardiometabolic Risk Factors: a Systematic Review and Meta-Analysis, Sports Medicine Open, 4(1) (2018) 35. [DOI] [PubMed]
[32]

C. Schou Andersen, M. Juhl, M. Gamborg, T.I. Sørensen, \& E.A. Nohr, Maternal Recreational Exercise during Pregnancy in relation to Children's BMI at 7 Years of Age, International Journal of Pediatrics, 2012 (2012) 920583. [DOI] [PubMed]

[33] J.F. Clapp 3rd, S. Simonian, B. Lopez, S. Appleby-Wineberg, \& R. Harcar-Sevcik, The One-Year Morphometric and Neurodevelopmental Outcome of the Offspring of Women Who Continued to Exercise Regularly Throughout Pregnancy, American Journal of Obstetrics and Gynecology, 178(3) (1998) 594-599. [DOI] [PubMed]

[34] L.A. Haakstad, \& K. Bo, Effect of Regular Exercise on Prevention of Excessive Weight Gain in Pregnancy: A Randomised Controlled Trial, European Journal of Contraception and Reproductive Health Care, 16 (2011) 116-125. [DOI] [PubMed]

[35] L. Meander, M. Lindqvist, I. Mogren, J. Sandlund, C.E. West, \& M. Domellöf, Physical Activity and Sedentary Time During Pregnancy and Associations with Maternal and Fetal Health Outcomes: An Epidemiological Study, BMC Pregnancy Childbirth, 21(1) (2021) 166. [DOI] [PubMed]

[36] M. Morales-Suárez-Varela, E. Clemente-Bosch, I. Peraita-Costa, A. Llopis-Morales, I. Martínez, \&A. Llopis-González, Maternal Physical Activity During Pregnancy and the Effect on the Mother and Newborn: A Systematic Review, Journal of Physical Activity and Health, 18(1) (2020)130147. [DOI] [PubMed]

[37] B. Muktabhant, T.A Lawrie, P. Lumbiganon, \& M. Laopaiboon, Diet or Exercise, or Both, for Preventing Excessive Weight Gain in Pregnancy, Cochrane Database Systematic Reviews,6 (2015) CD007145. [DOI] [PubMed]

[38] D. Aune, S. Schlesinger, T. Henriksen, O.D. Saugstad, \& S. Tonstad, Physical Activity and the Risk of Preterm Birth: A Systematic Review and Meta-Analysis of Epidemiological Studies, BJOG, 124(12) (2017) 1816-1826. [DOI] [PubMed]

[39] K. Dejong, A. Olyaei, \& J.O. Lo, Alcohol Use in Pregnancy, Clinical Obstetrics and Gynecology, 62(1), (2019) 142-155. [DOI] [PubMed]

\section{Acknowledgement}

The authors thank all the study subjects for their willingness to take part. 


\section{Funding}

No funding was received for conducting this study.

\section{Authors Contribution}

Konstantinos D. Tambalis designed the study, performed the data collection and analysis, and wrote the paper. Giannis Arnaoutis participated in the design of the study and critically reviewed the paper. Labros S. Sidossis was involved in the study design, manuscript writing, and overall supervision of the study. All the authors read and approved the final version of the draft.

\section{Ethics Approval}

The study was approved by the Bioethics Committee of Harokopio University. The study also had the approval of the relevant department of the Ministry of Education.

\section{Informed Consent}

Oral approval was obtained from all mothers who agreed to participate in the study and written informed consent was obtained from those participants who took part in the validation process of the study.

\section{Availability of data and material}

No additional data are available.

\section{Conflict of interest}

The authors declare that they have no conflict of interest.

\section{Does this article screened for similarity?}

Yes

\section{About The License}

(C) The author(s) 2022. The text of this article is open access and licensed under a Creative Commons Attribution 4.0 International License 